\title{
Social media monitoring: Responsive governance in the shadow of surveillance?
}

\author{
Victor Bekkers \\ Arthur Edwards (corresponding author) \\ Dennis de Kool
}

\author{
Erasmus University Rotterdam \\ Department of Public Administration \\ P.O. Box 1738, room T17-34 \\ 3000 DR Rotterdam
}

The Netherlands

edwards@fsw.eur.nl

Tel. +31.10.4082395

\begin{abstract}
Social media monitoring, which promises several advantages such as early warning and reputation management, is gradually becoming common practice in public organizations in the Netherlands. From a citizen's point of view, it can contribute to the responsiveness of public policies. However, social media monitoring also poses questions in terms of transparency and privacy. This paper investigates four cases of social media monitoring by Dutch public organizations. Policy departments are more strongly orientated towards monitoring, whereas organizations involved in policy implementation seem to be more inclined to progress to webcare. The paper argues for more transparency on social media monitoring.
\end{abstract}

Keywords: social media, social media monitoring, webcare, responsiveness, surveillance

To cite this article: Bekkers, V., et al., (2013). Social media monitoring: Responsive governance in the shadow of control? Government Information Quarterly (30): 335-342. 


\section{Introduction}

Social media are rapidly penetrating the modern information society. This new generation of applications emphasizes the importance of user-participation, contentsharing, and network effects (e.g., O’Reilly, 2007). They facilitate a scale shift that makes the organization of collective action, with large numbers of participants, more efficient (Chadwick, 2009). The political potential of social media poses several challenges for public organizations. Strategic surprises may emerge from the rapid expansion of issues and ad hoc synchronization of messages in web-based protest politics (Bekkers, Edwards, Moody, \& Beunders, 2011; Shirky, 2011).

Public organizations may perceive a need for strategies to cope with these surprises. These strategies include monitoring citizens' communication and contentsharing on social media (cf. Sobkowicz, Kaschesky, \& Bouchard, 2012). This paper addresses the practice of web monitoring or, more specifically, social media monitoring by public organizations in the context of Western democracies. Social media monitoring is "the continuous systematic observation and analysis of social media networks and social communities” (Fensel, Leiter, \& Stavrakantonakis, 2012). In the Netherlands, social media monitoring is gradually becoming a common practice in public organizations, especially in national departments and autonomous agencies.

In terms of public values, social media monitoring entails some tensions. On the one hand, it can facilitate the tuning of policies to citizens' needs and demands, and this may result in more responsiveness. On the other hand, social media monitoring involves communication between ordinary citizens in virtual domains that they may perceive as private. This poses ethical questions, especially when the monitoring agency is not transparent regarding its monitoring activities vis-à-vis social media users. Our central research question is how public organizations use social media 
monitoring, for what purposes, and how they deal with aspects regarding responsiveness, privacy, and transparency. This paper aims to contribute to the intended scope of the special issue by highlighting government use of information from social media applications, how governmental agencies use these data from citizens to improve public policies, as well as how various goals and normative principles are involved in this. The empirical part of the paper addresses emerging practices of social media monitoring in four national public organizations in the Netherlands. Section 2 introduces web monitoring and social media monitoring, indicating the origins of these practices in the private sector. Section 3 presents three theoretical approaches to social media monitoring and introduces a normative framework for evaluating social media monitoring. Section 4 presents the research strategy and the analytical framework. Section 5 analyzes the four selected cases. Section 6 concludes and provides further reflections on this new phenomenon of social media monitoring by public organizations.

\section{Web monitoring and social media monitoring}

Monitoring activities have become a strong tradition within the public sector (Bouckaert, de Peuter, \& van Dooren, 2003; de Kool, 2007, 2008). Traditional monitoring involves signalizing relevant developments in the physical environment, for example in the domains of safety, education, and environmental policies. The rapid increase in internet and social media usage by citizens, security threats, and the possibility of strategic surprises have induced governments to develop various online monitoring strategies and tools. These include tools for tracking movements and transactions, intercepting communications, and reading and interpreting data (Bannister, 2005). Tools to access and follow relevant communications on social 
media are a new development (Sutton, 2009). A distinction can be made between web monitoring and webcare. Web monitoring can be, but is not necessarily, the first phase of webcare, which includes online communication with customers or citizens. In reactive webcare, messages are sent in a situation of two-way or dialogical communication, in which participating citizens may expect the organization to react to their individual comments. In proactive webcare, messages are sent unsolicitedly (van Noort \& Willemsen, 2011).

Various software tools are available for social media monitoring. Methodologically, social media monitoring can be performed in two different ways. One way is to feed the software program with a string of keywords, thus producing an overview of the instances of online communication and their locations (forums, Facebook pages, Twitter accounts, etc.) in which these keywords are used. The other way is to steer the program towards a specific set of discussion forums and social networking sites, and to search them for a number of keywords. In the second case in particular, permanent monitoring of online forums during a certain period of time may occur. Unlike traditional monitoring, social media monitoring is real time and continuously preoccupied with relevant issues throughout the year. Information with regard to urgent issues with a potentially significant impact will require immediate action. Other relevant, but less urgent, information can be more gradually incorporated into policies.

Social media monitoring has its origins in the private sector. Most publications about these practices and tools are handbooks for companies (e.g., Croll \& Power, 2009; Steimel, Halemba, \& Dimitrova, 2010; Sen, 2011). Broadly speaking, these practices are aimed at strategic marketing and reputation management. Companies use 
social media monitoring for purposes relating to market research and early warning, trend scouting, and consumer feedback (Croll \& Power, 2009; Steimel et al., 2010).

\section{Theoretical framework}

\subsection{Three approaches to social media monitoring}

Monitoring is often approached as a rational instrument for gathering information. However, a rational-instrumental approach is too narrow with respect to understanding the complex character of monitoring and the policy processes in which it is embedded. A multiple perspective approach offers a better understanding of monitoring than a single rational perspective. For this reason, we make a distinction between three approaches to social media monitoring, namely, a rational-instrumental, a political-strategic, and a communicative approach. These approaches, derived from Habermas' theory of communicative action (Habermas 1981/1984), are analytically distinct in that they start from different premises about the relationship between the monitoring organization and the monitored subjects. However, the motives and actions of a monitoring organization can exhibit features of more than one approach. The approaches characterize types of organizational practices, but they do not exclude one another at the level of an organization.

\subsubsection{Rational-instrumental approach}

Rational-instrumental action aims at realizing pre-given goals on the basis of (1) information about the status-quo in the environment and (2) nomological knowledge about effective interventions. This means that social media monitoring is primarily conceived of as a means to find out what is going on in the virtual world in order to intervene in this environment with communication that can be expected to be 
successful in accomplishing certain policy goals. Monitoring is associated with the strong notion ‘to measure is to know’ (Van Gunsteren, 1976).

The main advantage of social media monitoring within this approach is that it can be a useful tool to identify relevant trends in society, for example opinions of citizens and target groups about specific policy issues. More specifically, social media monitoring can be a promising tool to ascertain new developments in the virtual world. Early warning and dealing with new challenges are important elements of strategic issue management (Heath \& Palenchar, 2009). Furthermore, social media monitoring, if embedded in webcare, can be used to correct false, incomplete, or misperceived statements of citizens on social media. The quest for more responsiveness is in this approach a top-down process aimed at fine-tuning policies within the existing policy framework.

Within the rational-instrumental approach, social media monitoring also faces several risks. First, the reliability and quality of information shared in social media can be doubtful (Beer \& Burrows, 2007). Generally speaking, there is a strong perception that an overwhelming amount of irrelevant 'noise' and 'chatter' flows through social media outlets (Carr, 2005; Sutton, 2009). Furthermore, social media can distribute and enlarge news very quickly, potentially leading to lots of attention on incidents and misconceptions of the day. Third, it is often unclear whether the participants in social media are representative of a larger group. It is a real challenge to select and interpret the relevant and representative signals from the mass of online interactions. An important risk of social media monitoring is that it can result in information overload, which can result in a 'paradox of choices,' in which one cannot see the wood for the trees (Schwartz, 2004). For all these reasons, social media 
monitoring can entail an overestimation of the signalizing power of public sector organizations.

\subsubsection{Political-strategic approach}

In strategic action, the actor acknowledges the presence of other actors in the environment who have their own goals and action plans. The success of strategic action depends on (1) knowledge about the goals and power resources of other relevant players, (2) a calculation of their action alternatives, and (3) a calculation of the appropriate action alternatives in one’s own hands. In the political-strategic approach, information is seen as a source and object of power (Pfeffer, 1992). Information generated by social media monitoring can be used by government agencies to serve their policy goals and organizational interests, for example to find out what is being said about the agency and its policies. In this way, social media monitoring and webcare can contribute to online reputation management. Through webcare, government agencies can try to mitigate (potential) resistance against a policy measure by influencing citizens' points of view in certain directions. In this context, one can speak about 'strategic communication'.

However, online interactions with citizens and clients are politically risky. Statements or messages on social media sent by public organizations can be wrong, misperceived, or unwelcomed by citizens, thereby harming the public organizations' reputation. Specific conditions pertaining to the character of public organizations also constrain the use of webcare for strategic communication. Government organizations face some formal restrictions and regulations in their interactions with citizens because in representative democracies they have to consider the primacy of politics. Political decision makers function within a highly politicized environment. Public 
servants always have to ensure that their statements are consistent with the policies endorsed by the political decision makers.

\subsubsection{Communicative approach}

In communicative action, two or more actors aim to coordinate their individual action plans on the basis of a shared definition of the situation. Actors try to reach consensus, at least partially, about the interpretation of a problem, on the basis of a shared stock of knowledge. Within this approach, social media monitoring is embedded in the broader process of webcare, if this is aimed at a co-production of policies (Linders, 2012) on the basis of a shared problem definition. The first stage involves gathering information about citizens’ perceptions, grievances, and demands, and getting feedback about policies that are being developed or implemented. In the second stage, government organizations react to, and interact by organizing, ‘collective intelligence’ (Surowiecki, 2004). This can result in new ideas and lead to policies that are better attuned to the problems experienced on the 'work floor' of public policies and in the life world of citizens.

An important risk in this communicative approach is that monitoring can be perceived as an unwelcome interference in peer-to-peer interactions or even a violation of 'privacy' in the domain of social media. The participation of public servants in online discussions could result in a 'big brother is watching you' feeling among other internet users. Furthermore, webcare raises certain expectations among the participants. Within a communicative approach, a government agency has to be sincere and consistent in its behavior, in terms of giving serious attention to citizens' wishes and grievances, and providing room for real cooperation in designing policies. 
The risks mentioned in section 3.1.2 concerning the political primacy in representative democracy also apply.

\subsection{Normative aspects of social media monitoring}

Lyon (2001, p. 2) defines surveillance as "any collection and processing of personal data, whether identifiable or not, for the purpose of influencing or managing those whose data have been garnered.” This definition suggests that a surveillance perspective on social media monitoring applies when (1) statements of individual social media users are observed and analyzed, (2) with the purpose of using this information to influence their points of view and behavior. Webster (2012, p. 255) argues that a surveillance perspective to the use of ICTs highlights "who collects what information, how this is achieved and for what purposes” and how information flows "are vested with interests and determine the nature of key relationships in society”.

Seen within a surveillance perspective, social media monitoring poses several normative questions. These questions deal with the purposes for which the content generated by social media monitoring can be used and the limits that have to be taken into account in terms of privacy and other values. A distinction can be made between (1) driving principles, (2) underpinning principles, and (3) process-based principles (Prins, Broeder, Griffioen, Keizer, \& Keymolen, 2011). The driving principles are “those related to government's drive to utilize ICT in all kinds of domains. [They] focus on improvement and quality gains” (p. 66). Security, effectiveness, and efficiency are mentioned as examples. Responsiveness, on which we focus in this paper, can be seen as another driving principle. Underpinning principles have to do with “guaranteeing rights and freedoms, charting 'silent losses' as the process of digitization unfolds, and protecting the autonomy of the individual” (p.66). We 
discuss privacy as the primary underpinning principle with regard to social media monitoring. Process-based principles provide "the procedural framework that makes a balanced comparison between the involved driving and underpinning principles possible” (p.66). We adopt the principles of transparency and accountability in our discussion.

\subsubsection{Driving principles of social media monitoring}

The three theoretical approaches indicate that the main driving principles of social media monitoring are effectiveness, strategic control, and responsiveness. Lyon (2001) identifies two faces of surveillance, namely, care and control. These two faces equally apply to social media monitoring. The care aspect catches the theme of responsiveness, whereas the control aspect refers to various purposes for which public organizations can use social media monitoring according to the rational-instrumental and strategic approaches, such as early warning and influencing opinions among target groups. The control aspect fits within what Beniger (1986) calls 'the control revolution' that extends through modern organizations, and, according to Lyon (1998), represents the logic behind modern surveillance of many kinds.

Social media monitoring can facilitate more responsiveness in policymaking. This can be accomplished in a top-down manner by fine-tuning communicative messages and policy content to citizens' wishes. However, it can also be used to facilitate governance processes in which citizens participate on a more or less equal footing with public officials, and in which public organizations take into account the ideas and suggestions expressed by citizens. The emergence of the governance paradigm since the 1990s reflects the attention that should be paid to the network interactions through which actors with different interests, beliefs, and resources co-produce 
policies (e.g., Sørensen \& Torfing, 2007). Social media constitute a new challenge to the classic government paradigm, because they can facilitate bottom-up participation and self-organization. It is interesting to see how social media monitoring in conjunction with webcare can support co-production with citizens and responsiveness. We expect agencies involved in policy implementation to be in a better position to accomplish this, because they operate in a less politicized environment than national departments.

\subsubsection{Underpinning principles of social media monitoring}

The notion of 'personal data' in Lyon's definition refers to the private sphere and the principle of privacy. The distinction between the public and private domains of online activities is a common theme in the literature on the ethics of content analysis of online forums. The privacy of an online forum can be approached in terms of technical accessibility or from the point of view of privacy as experienced by the participants (Bakardjieva \& Feenberg, 2000). 'Perceived privacy’ denotes “the degree to which group members perceive their messages to be private to that group” (King, 1996, p. 126). If citizens' online activities take place in blogs and discussion forums that are (perceived by them as) public, social media monitoring can be seen as an extension of traditional media monitoring directed at gauging public opinion on political issues. In such cases, one could even argue that online messages are public acts deliberately intended for public attention and consumption. Few ethical considerations seem to apply when these communications are used for social media monitoring. When citizens communicate on networks that they perceive as private, social media monitoring can be seen as an unwelcome intrusion into their private sphere (cf. Eggers, 2007; Beer \& Burrows, 2007). If the perceived privacy of a social 
network is higher, there is a greater need to approach the network as protected. De Koster (2010) formulates several indicators to measure perceived privacy. One indicator refers to the content of the forum messages, in terms of members' tolerance of 'outsiders.' In this context, we make a distinction between personal issues, which have strong bearings on private life, and societal issues, which refer primarily to societal problems. This distinction is one of degree (see also: King, 1996). Examples of personal issues include obesity and vaccination. However, these issues also have societal ramifications and have reached policy-agenda status. See Table 1 for some examples. In section 4, we will relate our four cases to this categorization of issues.

\section{Table 1}

Characteristics of online forums (with examples)

\section{Discussion}

Personal issues Societal issues

\begin{tabular}{ll|l}
\hline Perceived privacy is high & $\begin{array}{l}\text { Forum to discuss personal } \\
\text { health issues I }\end{array}$ & porum to share controversial \\
\cline { 2 - 3 } Perceived privacy is low & $\begin{array}{l}\text { Local website to inform one } \\
\text { another about nuisance in the }\end{array}$ & Forum to discuss environmental \\
neighborhood IV IV & \\
\hline
\end{tabular}

We may conclude that no universal guidelines can be formulated and that ethical decisions must be made for each social media monitoring activity separately. Public organizations can make different ethical decisions based on their organizational goals. Social media monitoring by the police and security services for enforcement and public safety has a different function than social media monitoring by policy departments. 


\subsubsection{Process-based principles of social media monitoring}

Prins et al. (2011, p.74) argue that citizens require two forms of transparency: first of all, the kind that allows them (at a macro level) to scrutinize the political and policymaking process in relation to the use of online strategies for gathering information, and, secondly, the kind that allows them (at a micro level) to scrutinize specific decisions and practices, and how these affect their individual rights. This means that public organizations should be transparent about their use of social media monitoring in policymaking in general as well as in individual cases, in particular when they use the method of monitoring specific forums and networks on a more or less permanent basis. The importance of macro-transparency lies in the possibility of an informed public discussion about the pros and cons of social media monitoring for public goals. Micro-transparency is a condition for obtaining users' informed consent, if doubts can be raised about the public character of their communications. In such cases, the covert nature of social media monitoring could be seen as an invasion of the perceived privacy of a social network. Transparency is a necessary condition for accountability. Accountability allows citizens to challenge policies, decisions, and practices, especially in terms of weighing the driving principles against the underpinning principles.

\section{Research design}

\subsection{Research strategy}

The research strategy is based on a multiple case study approach. A case study recognizes the complex nature of social phenomena in a coherent and integrated way, thereby acknowledging the complex and meaningful interaction between relevant social processes and actors instead of limiting the study of social phenomena to a very 
specified set of variables and the relations between them (Yin, 2003). We have selected four cases. Two cases concern social media monitoring in the context of policymaking; the other two cases focus on social media monitoring in the context of policy implementation and service delivery.

The first case is the Ministry of Education, Culture, and Science. In the aftermath of a revolt of Dutch secondary school students in 2007, the ministry developed an online monitoring strategy. The second case concerns the ministry responsible for infrastructure and the environment. The publicity in January 2010 about errors in the Fourth Assessment Report (2007) of the Intergovernmental Panel on Climate Change (IPCC) resulted in fierce discussions on various online forums about climate policy. The ministry commissioned web monitoring with the aim of getting an overall picture of these discussions. Both ministries were pioneers in social media monitoring among Dutch public organizations. The two cases differ on their position on the publicprivate dimensions in Table 1. Climate change is a societal issue, and the discussions took place on easily accessible public online discussion forums and blogs. The online discussion on climate change can be placed in box III in Table 1. The discussions on the subject of the student revolt were partly performed in the public sphere as well, but also on semi-private social networking sites visited by secondary school students. The issue has some ramifications for the intimate relationships between secondary school students and their teachers. These discussions can be placed, at least partly, in boxes I and II. The third case is the Dutch Tax and Customs Administration. This organization started web monitoring activities in 2009. Two years later, the webcare domain was explored by a Twitter experiment around citizens’ questions about tax returns. More webcare pilots followed afterwards. The fourth case is the Employee Insurances Implementing Agency. This agency formed a webcare team in 2009 with 
the idea of increasing customer satisfaction. The forums where taxpayers and unemployed people discuss their problems and experiences with the two public agencies can be placed in the domain of personal issues. The perceived privacy is probably medium or rather high (between boxes I and IV).

We used different research techniques to collect the empirical data, namely, a combination of desk research and semi-structured interviews. The interviews were conducted in two time periods. In 2010, 14 key players were interviewed in the two ministries. In 2012 and 2013, we conducted interviews with six public servants responsible for social media monitoring within the four organizations, including three in the tax agency and one with the employees' insurance agency. Some additional questions to the two agencies were answered by e-mail.

\subsection{Analytical framework}

Our analytical framework, presented in Table 2, consists of a framework of topics and items for the description of cases, combined with key characteristics of the three theoretical approaches referring to the goals of social media monitoring and its usage. This framework also covers the topics discussed in the second round of interviews.

Table 2

Analytical framework

\begin{tabular}{lcl}
\hline Primary topics & Research items/characteristics \\
\hline Goals & - & Goals of social media monitoring \\
& - & If social media monitoring is first phase of webcare: goals of webcare \\
& R-I/A: effectiveness \\
& S-P/A: reputation management \\
& C/A: dialogue \\
Way of operating & $-\quad$ Selection of relevant online forums and communities
\end{tabular}


- Selection of relevant communication

- $\quad$ Performers of social media monitoring within the organization

- Analysis of communication

- $\quad$ Position of webcare in communication package of the organization

- $\quad$ Performers of webcare in the organization

Surveillance

- $\quad$ Openness towards social media users

Usage

- $\quad$ Usage of results of social media monitoring and webcare, e.g.,

R-I/A: fine-tuning

S-P/A: preventing possible resistance

C/A: co-production of policies

Effects

- $\quad$ Effectiveness, strategic control, responsiveness

- $\quad$ Costs and benefits (efficiency)

\section{Analysis}

\subsection{The Ministry of Education, Culture, and Science}

\subsubsection{The secondary school students' revolt (2007)}

The introduction of major reforms in primary and secondary education during the last decade caused the quality of education to be a widely discussed issue in the Netherlands. In 2007, discussion focused on one particular issue: the government's enforcement of the 1,040-hour norm. This norm refers to the total number of teaching hours that students are required to follow each year during the first and second years of secondary education. Many schools were unable to comply with this norm because of teacher shortages. Such schools were forced to take a variety of phony measures suggesting that students were receiving education. Students complained that they were forced to be at school, without taking classes. In November 2007, students across the country revolted against the perceived absurdity of this norm. 
Social media, especially MSN and Hyves (a Dutch equivalent of Facebook), played an important role in mobilizing the students. At the ministry, policymakers and the deputy minister in charge were surprised by the scale of the protest and the speed of organization of the protest actions, as well as the mobilization strength that the internet and social media provided to the protesting students. No procedures were available at the policy department on how to react to these new, social network-driven forms of protest politics. No knowledge or staff were available to deal with this kind of protest. During the peak of the revolt, policymakers adhered to the established standard operating procedures, thereby relying on their access to the traditional media, to counterbalance the claims of the students. Before then, online discussions had not been seen as relevant sources of information. Policymakers were primarily focused on the opinions and information offered by the vested organizations in the field of secondary education as well as on the coverage of the events in the traditional media. They were confused about "whether and how they should react and which media they should use to inform students and the wider public on their views” (interview). The department decided to use the traditional media. One consideration was that the department was somewhat resistant to penetrate the virtual networks of students, because this could have counterproductive consequences. For policymakers, it was also difficult to pin-point the locations of the discussions. Although they were able to locate some relevant websites and networks, they had the impression that the use of, for instance, MSN made the discussion not only very fluid, but also rather invisible. As a result of these experiences, the ministry developed an online monitoring strategy to signalize discussions in the virtual domain about education-related issues at an early stage. It was considered that online early warning systems could reduce the risk of the department being surprised and confronted with new issues and unforeseen 
protests. Online monitoring would provide the department with a digital scan of online discussions; this was seen as a useful extra source of information in addition to traditional media monitoring. The protests of secondary school students against the 1,040-hour norm have been a wake up-call for developing this strategy within the new division Knowledge about the Environment and Communication (Afdeling Omgevingskennis en Communicatie). Public servants have become more aware of the need to monitor the environment permanently to find out what people (teachers, students, parents) say and think about policy programs and policy intentions.

\subsubsection{Current practice of social media monitoring}

Goals - The ministry's aims in relation to social media monitoring are described in terms of "getting policies better understood and therefore possibly better accepted" or “touching your target groups” (interview). One has to become acquainted with what matters within the target group. Responsiveness is an important value in this respect, but it has to be weighed against other (political) considerations. Other, more specific aims of social media monitoring are to ascertain the differences in viewpoints and sentiments among citizens about policy measures and to discover unexpected points of view that are not (yet) represented in the debate in the traditional media.

Way of operating - There is a small specialized unit for social media monitoring at the ministry’s Communication Directorate. They concentrate on policy priorities. The monitoring method consists of feeding software tools with selected keywords. The tools scan the internet and produce overviews of instances of communication, with the online locations where these keywords are used. Further analyses focus on argumentation patterns. Of special interest are new arguments that are cropping up. Several public servants have their own selection of relevant networks and online 
forums on their list of favorites. In this case, particular sets of networks and forums are monitored more or less permanently. The ministry has its own Twitter account and Facebook page. Specific questions from pupils and students can be responded to by placing links or by approaching students individually for further contact by phone or e-mail.

Surveillance - The ministry takes the line that everybody whose communication is publicly accessible can be considered to be aware that he or she can be followed up. This means that (in most cases) the monitoring practice has a covert nature. For some social networks, such as LinkedIn, one has to open an account; this implies that the ministry has to announce itself to the network manager. Tapping communication from communities that social media users have protected as private, however, would have serious political consequences. The ministry is always transparent about its involvement in webcare when giving answers to individual questions.

Usage - Social media monitoring has gained a fully-fledged position within the ministry’s communication architecture. The results of social media monitoring are used in the ministry's broader communication policies, alongside the results of traditional media monitoring and regular public opinion surveys. In crisis-like situations, the results are directly channeled to the political decision makers and the ministry’s spokespersons. In other cases, the results are gradually embedded in policies.

Effects - In some cases, the results have a bearing on the regular consultations with interest groups from the field, especially when the sentiments and viewpoints voiced on social media by, for instance, students are different from those expressed by their institutional representatives. Monitoring can also serve an anticipatory function. Prior to student actions, for instance, the ministry is able to infer from the intensity of 
sentiments expressed on social media how large the action will be. This information enables the ministry in taking appropriate action. These effects can be taken as additional indications of a monitoring practice according to the political-strategic approach ('strategic control').

\subsection{The Ministry of Infrastructure and the Environment}

\subsubsection{The climate debate (2009-2010)}

End November 2009, a few weeks before the Copenhagen Summit on climate change, several thousand e-mails and other documents from researchers at the University of East Anglia’s Climatic Research Institute were copied to various locations on the internet. These documents raised some doubts on the researchers' scientific integrity. In late January 2010, several errors were identified in the 2007 IPCC report. For the policymakers at the ministry, the publicity about these incidents appeared to be politically threatening. The prevailing view was that they could seriously damage the ministry's public line of defense regarding the scientific basis of climate policy.

The ministry decided to commission web monitoring. In February and March 2010, the research agency Politiek Online provided daily reports as well as overviews of the discussions every week. Data included who were reacting, where, how often, the sentiments (pro, contra, or neutral), and tone of voice. The data about 'who, where, and how often' were provided by overviews that accompanied the weekly reports. For one week in February 2010, a list of the 272 participants (with their nicknames or, if they used them, their pseudonyms or real names) in a sample of 18 online discussions was provided, with the number of their posts. The names of 
persons who participated in more than one discussion were marked. ${ }^{1}$ In an internal memorandum (dated 21 April 2010), a public servant responsible for the monitoring project expressed his interest in getting to know the connectors, gatekeepers, or influentials (see: Gladwell, 2000): “The gatekeepers could perhaps perform the role of ambassadors for our message.” This might be interpreted as a tendency towards 'strategic communication.' The weekly reports also provided overviews of the main themes discussed during that week, as well as shifts in the focal locations of the discussions. The reports indicated that the discussions were characterized by strong polarization, less in terms of confrontations on the individual sites than in terms of differentiation among the sites. As a result, the protagonists and antagonists were “hardly able to meet each other at all” (Politiek Online, 2010). ${ }^{2}$ The discussions were marked by a strong distrust of government and science. The reports provided the ministry some advice regarding communication policy, including the suggestion to react on its own web site to discussions, especially on articles of climate skeptical journalists, or to actually participate in online discussions. The researchers suggested that online forums, where the polarization was not so high, might be suitable for this. The ministry decided not to participate in the discussions because this was considered politically too risky. However, the events brought about a notable shift in policymakers' attitudes towards the skeptics. There were signs of a more positive attitude towards the involvement of skeptics in the climate debate (interview), with the result that skeptics were invited to attend meetings at the ministry.

\subsubsection{Current practice of social media monitoring}

\footnotetext{
${ }^{1}$ This might be a violation of the European data protection directive (Directive 95/46/ES) if such a practice facilitates the identification of natural persons.

${ }^{2}$ This phenomenon refers to the issue of 'balkanization' of the online discussion domain (Sunstein, 2001).
} 
Goals - Many decisions have traditionally been taken on the basis of the ministry's own research in relation to its environment. Originally, this research was based on three pillars: traditional media monitoring, stakeholder analyses, and public opinion surveys. Social media monitoring is the most recent fourth pillar. The leading motive behind social media monitoring is to get a better insight into what is going on in the social environment and not to be surprised by unexpected resistance. Monitoring can be the first phase of webcare. In the interview, the public servant observed than when performed well and in an early phase of the policy cycle, social media monitoring can also serve to avoid webcare. The results can be used in the information accompanying a policy measure after the political decision has been made to implement it, with the aim of preventing possible resistance. This is a clear example of social media monitoring according to a political-strategic approach.

Way of operating - A large part of the monitoring activities focuses on Twitter. The use of Twitter by parliamentarians, local politicians, stakeholders, environmental groups, experts, and other insiders can be seen as a springboard to information from other sources, including blog discussions and online forums. Alongside Twitter, the most important news forums are monitored, including the online forums of newspapers. Complementarily to this, and especially when certain issues are pertinent, other forums are monitored as well. Simple keywords are used, such as the name of the minister. Social media monitoring is implemented by four analysts within the ministry’s central Communication Directorate. Public servants in specific issue domains within the ministry can also monitor what is said and written about their subjects. With the existing focus on Twitter, webcare proceeds primarily by providing individual answers when serious and substantive questions are posed. The ministry also acts pro-actively by sending Tweets in order to eliminate possible questions. 
Surveillance - Because of its focus on Twitter, the ministry judges that no ethical considerations apply: “Active users of Twitter want to be followed” (interview). Monitoring activities thus have a covert nature. However, the ministry is always transparent about its involvement in webcare when giving answers to individual questions.

Usage - Social media monitoring has gained a fully-fledged position within its information and communication architecture. Results of social media monitoring can be used as input for the ministry's messages to the outside world. If signals have a certain urgency, they are directly channeled to the public relations officers. Otherwise, overviews and analyses are made and shared within the Communication Directorate and the leading managers of the policy directorates concerned.

Effects - The effects of social media monitoring are difficult to establish. According to the interviewee, further improvements have to be made in translating results of monitoring into concrete action. In terms of efficiency, there are no extra costs because the monitoring team is recruited from other research staff.

\subsection{The Dutch Tax and Customs Administration}

The interest in web monitoring that had been gradually taking hold in the tax agency (Belastingdienst) was given concrete form in 2009. This interest was not triggered by a 'strategic surprise,' as was the case for the two ministries.

Goals - The primary goal of social media monitoring is to gain insight into taxpayers' sentiments about taxes and their images of the organization. Many sentiments on the internet are fuelled by the traditional press: "Popular moods in the traditional media often result in a snowball effect on social media” (interview). A 
second goal is to gain a better insight into the questions and problems that clients have with their tax returns.

Way of operating - The agency uses both methods of monitoring mentioned in section 2. Keywords are used to scan the online environment for issues that are relevant for the agency. The agency also focuses more or less permanently on a small set of online communities where members of important target groups communicate about tax issues. An example is the website higherlevel.nl for entrepreneurs with innovative ideas. Until now, the number of personnel engaged in social media monitoring has been very limited, but the agency's ambition is to enlarge this capacity. Since 2011, the agency has launched various experiments with webcare, including a Twitter experiment to help people with filling in their tax return form. This experiment has been celebrated as a success within the organization. Since 2012, the webcare team has been present on some online forums, including higherlevel.nl, with reactive webcare (direct interaction). Only small steps are being taken in webcare because of the (potential and perceived) risks of interaction with citizens, for example by making errors that can damage the reputation of the organization.

Surveillance - As in the other three cases, the agency is transparent about its involvement when giving answers to taxpayers' questions. Because of the agency's presence on some online forums with reactive webcare, participants can be aware of the agency's presence in terms of monitoring as well.

Usage - Insights yielded by social media monitoring into the sentiments of taxpayers can lead to concrete interventions in the context of reputation management. Effects - An analysis of the Twitter experiments showed that the community appreciated this initiative and that many questions were answered (Media Intelligence, 2012). According to our interviewee, it is very difficult to measure the 
effects of webcare, specifically to ascertain whether it leads to adjusted images about the organization and gains in terms of efficiency and quality of service delivery.

\subsection{Employee Insurances Implementing Agency}

The Employee Insurances Implementing Agency (UWV) is an autonomous agency that implements the laws and regulations on unemployment benefits and employment reintegration. Against the background of a thorough reorganization process aimed at more efficiency and client satisfaction, the UWV decided to use the internet as its primary communication channel. In 2009, the organization started a pilot with web monitoring, one year later followed by webcare.

Goal - The primary goal of webcare is to help clients with their questions in their own virtual environment. The web monitoring pilot revealed that clients often pose questions to one another about benefits and regulations. In quite a few cases however, they got wrong answers from other people. Another goal concerns the conversion from individual answers by telephone to answers within an online community, which is more efficient for the organization. Reputation management is not a primary goal of web monitoring and webcare; rather, it is seen as a byproduct of better service and more client satisfaction.

Way of operating - The UWV uses both methods of web monitoring, i.e., web search by key words and monitoring specific forums. The webcare team consists of about five experienced employees of the Client Contact Center. Special attention is given to complaints. In most cases, questions are dealt with by placing links in communities to information on the UWV's website. In this way, the UWV maintains unity in information provision and tries to strengthen clients' self-reliance. Clients with complicated questions are contacted by telephone. 
Surveillance - At the beginning, when the webcare started, many negative reactions were encountered from clients who wondered why the UWV was penetrating 'their' communities. Since then, webmasters and moderators of communities and web forums have been informed beforehand about the UWV's virtual presence and the goals behind it. They then inform their forums and in this way often serve as ambassadors for the UWV. In November 2012, the webmasters' team of the 'partners- in-misfortune-forum' (lotgenotenforum.nl) congratulated the UWV's webcare team on winning the public's prize of Accenture Innovation Award!

Usage - The organization is trying to develop a more pro-active approach to information provision. As noted above, one important aim of webcare is to strengthen clients' autonomy and self-reliance in solving their problems. A further usage of the results of webcare would consist of offering products and services that make this possible. This can be seen as a specific way to enhance responsiveness.

Effects - According to our interviewee, the return on investment in webcare is difficult to establish. In terms of staffing, there are no extra costs because the webcare team is recruited from the Client Contact (call) Center. Gaining a better insight into the impact of webcare on efficiency and quality of service delivery is one of the UWV's priorities.

\subsection{Further analysis}

The three theoretical approaches enable us to distinguish 'typical practices' in public organizations' use of social media monitoring and webcare in policymaking and external communication. This involves analytical generalization, in which a case study seeks to generalize a particular set of results to some broader theory (Yin, 2003). Each approach can be tested in empirical research, thereby further elaborating 
the theory when it is used again in future research. The rational-instrumental approach is clearly present in the education ministry's ambition to be better informed about the feelings and viewpoints of target groups and other stakeholders. This information supports the fine-tuning of education policies and concomitant external communication, thereby enhancing the effectiveness and responsiveness of education policies. The strategic approach can be recognized in the tax agency's orientation towards gauging tax payers' sentiments for purposes of reputation management. The strategic approach is also visible in the two ministries' usage of results of social media monitoring in their interactions with external actors, for instance in the consultations with stakeholder organizations and in the fine-tuning of communicative messages with the aim of coping with or preventing possible resistance. The communicative approach might be visible in the case of the UWV. This agency integrates social media monitoring into webcare, aimed at strengthening clients’ autonomy and selfreliance in solving their problems. Whether this can be seen as a communicative approach, however, depends on whether the agency also integrates the problem definitions of its clients into the design of services. In that case, a quest for responsiveness comes somewhat closer to real co-production between the agency and its clients. In the other cases, responsiveness is more a byproduct of fine-tuning and strategic communication.

With regard to the surveillance aspect, the UWV stands out for its transparency about its presence in virtual communities. This transparency was more or less enforced by the participants when they challenged the agency's covert presence in 'their' community. This can also be taken as a sign of a communicative approach to social media monitoring and webcare. 


\section{Conclusions}

The cases suggest that among public organizations in the Netherlands social media monitoring is gaining a fully-fledged position alongside the more traditional ways of gauging sentiments and views among target groups and clients. We first summarize the most important results of our analysis.

For both ministries and the tax agency, the main goal of social media monitoring is to gain a better insight into the relevant sentiments within their target groups. Instrumental and strategic orientations prevail in this endeavor. For the UWV (and also the tax agency), the wish to help clients with their questions and problems is an important motive, alongside the quest for efficiency by a conversion from individual answers to answers within an online community. We distinguished two methods of social media monitoring. One way is to feed the software program with a string of keywords for broad online monitoring; the other way is to search a specific set of forums (on a more or less permanent basis) for a number of keywords. The investigated organizations use both methods, although the broad keyword search prevails within the national departments. For the two agencies, monitoring some specific forums is a condition for implementing reactive webcare on these forums. At the time of writing this paper, this form of webcare is not used by the two investigated national departments, possibly because of the complexities of participating in forums on policy issues in the highly politicized environments in which national departments operate. Ministries seem to engage more in pro-active webcare, although they also answer some questions individually. In the case of the UWV, some signs of a communicative approach, in terms of co-production, are visible. Real co-production would involve the direct participation of clients in product development on the basis of their problem definitions. Both ministries take the line that transparency about their 
monitoring practices is not necessary, because everybody whose communication is publicly accessible can be considered to be aware that he or she can be followed up. For the two agencies, a more open policy towards transparency became appropriate, as their webcare activities evolved towards a visible presence on online forums frequented by their target groups.

We have argued that ethical questions regarding privacy, transparency, and accountability crop up when organizations monitor online forums. Several aspects of social media monitoring have to be considered in this context, including (1) perceived privacy, (2) the method of monitoring, and (3) the covert nature of monitoring. The monitoring of networks that are perceived as private by their users, even when these forums are publicly accessible, can be seen as an intrusion into their life world. This is especially the case when a monitoring method is used whereby certain networks and forums are monitored more or less permanently. The UWV case shows that users have challenged this practice and forced the agency to inform them about its goals. We conclude that, in terms of micro-transparency, public organizations should be open about their monitoring practices towards social media users, particularly if reasonable doubts can be raised about the public character of their communications and the networks are monitored more or less permanently during a certain period of time. On the macro level of transparency, a concrete suggestion is that public organizations publicly report their social media monitoring activities annually. In this way, these organizations can be held accountable to the wider public. 


\section{References}

Bakardjieva, M., \& Feenberg, A. (2000). Involving the virtual subject. Ethics and Information Technology, 2, 233-240.

Bannister, F. (2005). The panoptic state: Privacy, surveillance and the balance of risk. Information Polity, 10, 65-78.

Beer, D., \& Burrows, R. (2007). Sociology and, of and in Web 2.0: Some initial considerations. Retrieved from http://www.socresonline.org.uk/12/5/17.html.

Bekkers, V.J.J.M., Edwards, A.R., Moody, R., \& Beunders, H. (2011). Caught by surprise? Micro-mobilization, new media and the management of strategic surprises. Public Management Review, 13(7), 1003-1021.

Beniger, J. (1986). The control revolution. Cambridge, MA: Harvard University Press.

Bouckaert, G., de Peuter, B., \& van Dooren, W. (2003). Meten en vergelijken van lokale bestuurlijke ontwikkeling: een monitoringsysteem voor het lokaal bestuur in Vlaanderen. Brugge: Die Keure.

Carr, N. (2005). The amorality of Web 2.0, Nicolas Carr's blog. Retrieved from http://www.roughtype.com/archives/2005/10/the_amorality_o.php

Chadwick, A. (2009). Web 2.0. New challenges for the study of e-democracy in an era of informational exuberance. I/S: A Journal of Law and Policy for the Information Society, 5, 9-41.

Croll, A., \& Power, S. (2009). Complete web monitoring. Sebastopol: O’Reilly. de Kool, D. (2007). Monitoring in beeld: een studie naar de doorwerking van monitors in interbestuurlijke relaties. PhD dissertation, Erasmus University, Rotterdam 
de Kool, D. (2008). Rational, political and cultural uses of performance monitors: The case of the Dutch urban policy. In W. van Dooren \& S. van de Walle (Eds.), Performance information in the public sector: How it is used (pp. 174-191). New York: Palgrave Macmillan.

de Koster, W. (2010). 'Nowhere I could talk like that': Togetherness and identity on online forums. PhD dissertation, Erasmus University, Rotterdam.

Eggers, W.D. (2007). Government 2.0: Using technology to improve education, cut red tape, reduce gridlock, and enhance democracy. Lanham, MD: Rowman \& Littlefield Publishers.

Fensel, D., Leiter, B., \& Stavrakantonakis, I. (2012). Social media monitoring. Innsbruck: Semantic Technology Institute. Retrieved from http://oc.sti2.at/sites/default/files/SMM\%20Handouts.pdf

Gladwell, M. (2000). The tipping point. New York: Little, Brown and Company. Habermas, J. (1981/1984). Theorie des kommunikativen Handelns. Frankfurt am Main: Suhrkamp (transl. The theory of communicative action. Boston: Beacon Press).

Heath, R. \& Palenchar, M. (2009). Strategic issues management. Thousand Oaks, CA: Sage.

King, S.A. (1996). Researching internet communities: Proposed ethical guidelines for the reporting of results. The Information Society: An International Journal, 12, $119-127$.

Linders, D. (2012). From e-government to we-government: Defining a typology for citizen coproduction in the age of social media. Government Information Quarterly, 29, 446-454. 
Lyon, D. (1998). The world wide web of surveillance: The internet and off-world power-flows. Information, Communication \& Society, 1(1), 91-105.

Lyon, D. (2001). Surveillance society: Monitoring everyday life. Buckingham: Open University Press.

Media Intelligence (2012). Twitter Analyse Belastingdienst. Leiden: Media Intelligence.

O’Reilly, T. (2007). What is Web 2.0: Design patterns and business models for the next generation of software. Communications and Strategies, 65, 17-37.

Pfeffer, J. (1992). Managing with power: Politics and influence in organizations. Boston, MA: Harvard Business School Press.

Politiek Online (2010). Monitoring Online Discussie Klimaat. 8 February 2010-11 March 2010. Den Haag: Politiek Online.

Prins, C., Broeder, D., Griffioen, H., Keizer H.G., \& Keymolen, E. (2011).

iGovernment. Amsterdam: Amsterdam University Press.

Schwartz, B. (2004). Paradox of choices: Why more is less. New York: Reed Publishers.

Sen, E. (2011). Social media monitoring für Unternehmen. Cologne: Social Media Verlag.

Shirky, C. (2011). The political power of social media. Foreign Affairs, 90, 28-41. Sobkowicz, P., Kaschesky, M., \& Bouchard, G. (2012). Opinion mining in social media: Modeling, simulating, and forecasting political opinions in the web. Government Information Quarterly, 29, 470-479.

Sørensen, E., \& Torfing, J. (2007). Theories of democratic network governance. Houndsmills, UK: Palgrave MacMillan. 
Steimel, B., Halemba, Chr., \& Dimitrova, T. (2010). Social media monitoring: Erst zuhören, dann mitreden in den Mitmachmedien! Meerbusch, Germany: MIND.

Sunstein, C. R. (2001). Republic.com. Princeton, NJ: Princeton University Press.

Surowiecki, J. (2004). The wisdom of crowds: Why the many are smarter than the few and how collective wisdom shapes business, economies, societies, and nations. New York: Doubleday.

Sutton, J.N. (2009) Social media monitoring and the democratic national convention: New tasks and emergent processes. Journal of Homeland Security and Emergency Management, 6, 1-20.

van Gunsteren, H.R. (1976). The quest for control. A critique of the rational-central rule approach in public affairs. London: John Wiley \& Sons.

van Noort, G., \& Willemsen, L.M. (2011). Online damage control: The effects of proactive versus reactive webcare interventions in consumer-generated and brand-generated platforms. Journal of Interactive Marketing, 26, 131-140.

Webster, C.W.R. (2012). Surveillance as X-ray. Information Polity, 17, 251-265.

Yin, R. (2003). Case study research: Design and methods. (3rd ed). Thousand Oaks, CA: Sage. 